\title{
Developing a new look
}

\author{
Olivier Pourquié ${ }^{1, *}$, Katherine Brown ${ }^{2}$ and Claire Moulton ${ }^{2}$
}

As you might have noticed, Development has been looking a little different recently, with a new website and a new masthead for the journal (see Box 1 for elements of our new branding). These changes mark the culmination of a series of projects we've been working on over the past year at The Company of Biologists, aimed at improving the experience for our readers and at promoting the activities and values of the Company. Our website (and those of our sister journals) has undergone more than just a visual makeover - we have de-cluttered our pages and improved navigability, and the new open source platform will allow us to implement additional functionalities in the future. The consistent design, applied across all our journals, the Company's own website (http://www.biologists.com/) and that of our community blog the Node (http://thenode.biologists.com) aims to provide clearer brand recognition and a better user experience we hope you like it!

Since you are reading this editorial, you are probably at least reasonably familiar with the journal, and many of you will know something about The Company of Biologists, the publisher behind it. But we'd like to take this opportunity to let you know a bit more about who we are, what we do and how we help the scientific community. The Company of Biologists is a not-for-profit organisation dedicated to supporting and inspiring the biological community. At the heart of the Company are our five journals - Development, Journal of Cell Science, Journal of Experimental Biology, Disease Models \& Mechanisms and Biology Open - and our primary mission is to publish influential and innovative science, providing a valuable forum for sharing scientific knowledge. Our journals cover a broad range of the life sciences, from comparative physiology to drug discovery, but they all aim to provide an important platform for their respective communities: to disseminate research to the community in an accessible manner and to make the publication process as pain-free as possible (for some of the benefits of publishing in Development, see Box 2). For example, at Development we recently changed the way we ask our reviewers to assess papers (Pourquié and Brown, 2015), with the aim of easing the path to publication while still maintaining our high standards. We hope this is making a difference for authors (we welcome your feedback), and we will continue to review and improve our processes.

Another way we have tried to help in reducing 'the pain to publish' is through our newest journal, Biology Open (BiO; http:// bio.biologists.org), which we launched as a response to community feedback. As a fully Open Access journal, $\mathrm{BiO}$ supports the rapid publication of scientifically sound research across the biological sciences, without making judgement on the 'impact' of the work. Importantly, papers rejected from Development can be transferred to $\mathrm{BiO}$, where their editors (including developmental biologists

\footnotetext{
${ }^{1}$ Harvard Medical School, Department of Genetics, Brigham and Women's Hospital, Department of Pathology, HIM118, 4 Blackfan Circle, Boston, MA 02115, USA. ${ }^{2}$ The Company of Biologists, Bidder Building, Station Road, Histon, Cambridge CB24 9LF, UK.

*Author for correspondence ( pourquieeicdev@igbmc.fr)
}

Anna-Katerina Hadjantonakis, Yishi Jin and Jenny Nichols) can use the Development referee reports to make swift decisions on the potential suitability of these papers for $\mathrm{BiO}$, thus streamlining the process and hopefully allowing authors to get their research results out to the community more quickly (see Box 3 for recent BiO papers of interest to the developmental biology community). While we know that developmental biologists have a wide choice of specialist journals to which they can submit, we believe that $\mathrm{BiO}$ provides a valuable alternative - particularly in cases where the prime objective is to get a paper published with minimum hassle.

Although our journals are our most important output, the Company is much more than just a publisher. As a UK-registered charity, we believe that the profits from publishing the hard work of biologists should support scientific discovery and help develop future scientists. Each year, we provide significant financial support to the community through our various charitable programmes, overseen by our dedicated Board of Directors - distinguished practising scientists who give up their time free of charge to help oversee the Company's activities.

So where does this money go? We run a very active Meeting Grants programme (http://www.biologists.com/grants/), providing support to help defray the significant costs of putting on a conference. We also believe in supporting young scientists to learn new techniques, make new scientific connections and experience different scientific cultures: our Travelling Fellowships provide funding for researchers to make collaborative visits to other labs (http://www.biologists.com/travelling-fellowships/; see also Box 4). We also provide large grants to several societies, including the British Society of Developmental Biology (BSDB; http://bsdb.org/). Part of this money is used by the society to help run its annual meeting, while the rest is dedicated to a travel grants programme, to which BSDB members of any nationality can apply for funding to help pay for attendance at conferences across the

Box 1. A new look for the Company and its journals The Company of Biologists logo:

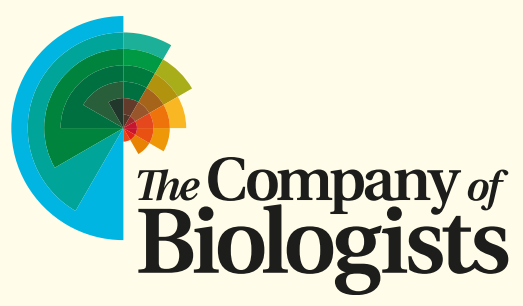

Development's new masthead:

\section{Development}


Box 2. Key information about the policies, processes and benefits of publishing in Development

- Free to publish: no page or colour charges.

- Editorial decisions made by expert Academic Editors who know and understand your field.

- Fast publication, online and in print.

- Avoidance of multiple rounds of review wherever possible; strong commitment to publishing invited revisions.

- Scoop protection: we won't reject your manuscript on the grounds that a competing paper has come out after yours was submitted.

- Author-pays Open Access publication option available.

- All articles freely available online six months after publication; online archive dating back to 1953.

- Open attitude to sharing research results and data on pre-print servers and data repositories.

- Informative and provocative Review and Hypothesis-type articles written by leaders in the field.

- All articles copyedited by experienced scientific editors.

Box 3. Recent developmental biology papers in BiO

Béatrice Brousse, Karine Magalon, Pascale Durbec and Myriam Cayre (2015). Region and dynamic specificities of adult neural stem cells and oligodendrocyte precursors in myelin regeneration in the mouse brain. Biol. Open 4, 980-992.

Erica M. McGreevy, Deepthi Vijayraghavan, Lance A. Davidson and Jeffrey D. Hildebrand (2015). Shroom3 functions downstream of planar cell polarity to regulate myosin II distribution and cellular organization during neural tube closure. Biol. Open 4, 186-196.

Richa Rikhy, Manos Mavrakis and Jennifer Lippincott-Schwartz (2015). Dynamin regulates metaphase furrow formation and plasma membrane compartmentalization in the syncytial Drosophila embryo. Biol. Open 4, 301-311.

Vahap Aydogan, Anna Lenard, Alexandru Stefan Denes, Loic Sauteur, Heinz-Georg Belting and Markus Affolter (2015). Endothelial cell division in angiogenic sprouts of differing cellular architecture. Biol. Open 4, 12591269 .

globe (see http://bsdb.org/membership/meeting-grants/companyof-biologists/).

More recently, we started hosting our own series of Workshops (http://www.biologists.com/workshops/), bringing together small groups of leading experts and young scientists (who can apply to attend with no registration fees) from a diverse range of scientific backgrounds for the cross-fertilisation of interdisciplinary ideas. The unique format of these Workshops has proved a huge success, with overwhelmingly positive feedback from organisers and participants alike, and we welcome proposals for future events. Finally, we are now organising Meetings on topics of particular interest to the journals (http://www.biologists.com/meetings/). The first of these focussed on the emerging field of human development (for a review of the Meeting, see Medvinsky and Livesey, 2015) and
Box 4. A Development Travelling Fellowship story: The benefits of global collaboration

Mirana Ramialison has been able set up her own lab at the Australian Regenerative Medicine Institute in Melbourne - thanks in part to Development.

Mirana had been a bioinformatician post-doc in the laboratory of Professor Richard Harvey, at the Victor Chang Cardiac Research Institute in Sydney. Her project consisted of deciphering the regulatory network that controls heart development and how this network might be perturbed in disease conditions, such as congenital heart disease. This involved genome-wide information obtained using a mouse cell line (HL1 cells). Mirana wanted to further investigate how this cardiac gene regulatory network changed (or not) during evolution. This new project required genome-wide information on cardiac-specific cells from different organisms, including zebrafish. The laboratory of Dr Eileen Furlong at EMBL Heidelberg in Germany had published a new method, BiTS-ChIP-seq (Bonn et al., 2012), that allows researchers to obtain genome-wide information from tissue-specific cell types in vivo. Mirana saw that using this method in the developing zebrafish, in a transgenic line that specifically labels heart nuclei, would help gain insight into the nature of this gene regulatory network in vivo.

The published protocol was detailed and complex and included many techniques that Mirana has never performed before. The quickest way to get these experiments going was to get 'hands-on' experience of this protocol - but Australia is far from Heidelberg. A Travelling Fellowship from The Company of Biologists made the visit possible, providing Mirana with the hands-on experience to learn the protocol and its 'tricks', saving months of trials to get it right.

The Travelling Fellowship also had repercussions beyond research; Mirana was in the process of looking for an independent position and finding grants to fund it. The collaboration with Dr Furlong's laboratory on the BiTS-ChIP-seq experiments gave the evidence of collaboration that the Australian Research Council needed. Not only did the Travelling Fellowship help save time on experiments, it strengthened connections around the world and helped Mirana to start her own laboratory.

was such a success that we will be running a second Meeting on the same topic in 2016 (see http://www.biologists.com/meetings/fromstem-cells-to-human-development-2016/) - we hope some of you will be able to join us!

We hope this brief overview of the activities of the Company has given you some idea of how we strive to help the scientific community. For further information, we encourage you to browse our website (http://www.biologists.com/) to see how you - whether you're starting out in your career or you're an established group leader - can benefit from what we do. Our ethos, 'Supporting biologists, inspiring biology', influences all that we do. We hope that by publishing in, reviewing for and reading Development you will continue to support the journal and the Company and, through us, the community at large.

\section{References}

Medvinsky, A. and Livesey, F. J. (2015). On human development: lessons from stem cell systems. Development 142, 17-20.

Pourquié, O. and Brown, K. (2015). Developing peer review. Development 142, 1389. 